\title{
Estruturas e padrões espaciais de povoamento em comunidades de faxinal
}

\author{
Spatial structures and patterns of settlement \\ in communities of faxinal
}

\section{Padrones y estructuras espaciales de poblamiento en comunidades de faxinal}

\author{
Joélcio Gonçalves Soares \\ joelciosoares@yahoo.com.br \\ Universidade Estadual de Ponta Grossa
}

Cicilian Luiza Löwen Sahr

cicilian@uol.com.br

Universidade Estadual de Ponta Grossa-PR

\begin{abstract}
Resumo: O presente artigo versa sobre os faxinais, comunidades tradicionais situadas na região Centro-Sul do estado do Paraná e que habitam áreas com o bioma das Matas com Araucária. Estas comunidades apresentam características intrínsecas no que se refere aos padrões de povoamento, suas estruturas e formas de ocupação e uso do solo, as quais são objeto de estudo neste artigo. Busca-se analisar como se estruturam estas características, procurando levantar quais fatores levam a tais configurações e, também, como estas se transformam ao longo dos anos.
\end{abstract}

Palavras-chave: Comunidades rurais. Estruturas de povoamento. Faxinais.

Abstract: The article presented here concerns about faxinais, traditional communities located in Central South Region of Paraná State that inhabit areas with the Forest of Araucaria Biome. These communities have intrinsic characteristics, report to the forms of occupation and use of land and its structures and patterns of settlement, which are object of study of the present article. It is intended to analyze how these features are structured, looking for what factors lead to such configurations and, also, how they change over the years.

Keywords: Rural communities. Settlement structure. Faxinais.

Resumen: Este artículo versa sobre los faxinais, comunidades tradicionales ubicadas en la región Centro-Sur del estado de Paraná y que viven en espacios con el Bioma de la floresta con Araucarias. Estas comunidades tienen características intrínsecas en relación a los padrones de poblamiento, estructuras, formas de ocupación y uso de la tierra, las cuales son objeto de estudio en este artículo. El objetivo eres analizar cómo se estructuran estas características, buscando identificar los factores que conducen a este tipo de configuraciones, y también, cómo éstos se transforman en los últimos años.

Palabras clave: Comunidades rurales. Estructuras de poblamiento. Faxinais. 


\section{INTRODUÇÃO}

O homem necessita, para existir, de uma comunidade, assim como esta depende dele para sua formação. Nesta relação de dependência, ocorre a geração de particularidades, que derivam de suas adaptações ao meio em seus diversos aspectos. Trata-se, portanto, de um processo mútuo que envolve, evidentemente, um grupo de pessoas e um local com o qual o grupo se identifica.

A vivência do grupo depende e se dá em determinado espaço. Sendo assim, os indivíduos buscam adaptar e/ou transformar determinado local em prol de suas necessidades. Isso ocorre desde a escolha do local, até a determinação da localização de suas residências, das terras mais apropriadas para o cultivo, além da proximidade a vias de circulação e fontes de água.

No que se refere ao grupo, para que sua convivência seja possível na forma de comunidade, há necessidade de processos de organização, que podem ocorrer por meio de relações de interação e cooperação social, com base em uma série de normas que norteiem as atitudes dos indivíduos. Quando essas relações existem e são respeitadas pela maioria, pode ocorrer a geração de uma forma de convívio com certa harmonia, e em decorrência disso, um aumento da força e união de todos em torno de preceitos e valores coletivos.

É com esta perspectiva que ao analisar as comunidades faxinalenses no Paraná, apreendendo suas dinâmicas espaciais, foram observadas estratégias que visam facilitar a sobrevivência individual e do grupo. Assim, este artigo tem como objetivo apresentar os padrões de povoamento, ocupação e uso do solo em comunidades tradicionais faxinalenses.

A inquietação que norteou e propiciou a realização deste estudo teve por base alguns estudos clássicos referentes a padrões de povoamento e suas estruturas e formas de ocupação e uso do solo, como os de Smith (1971), Leonard e Clifford (1971), Smith (1971), Bertrand (1973), Vasconcelos (1977) e Mendras (1978). Estes estudos foram produzidos a partir da análise de diversos tipos de comunidades. Procurou-se transpor a metodologia destes para a análise de comunidades de faxinal.

Para o desenvolvimento da pesquisa, em um primeiro momento, ocorreu a pesquisa bibliográfica, ou seja, a busca de livros, artigos, dissertações e outros trabalhos que versassem sobre as temáticas: a) padrões e estruturas de povoamento; e b) comunidades de faxinal. Uma vez obtido material para construção de referencial conceitual sobre os temas a serem discutidos, partiu-se para o estudo das comunidades, que ocorreu da seguinte forma: a) análise e comparação de comunidades em diferentes temporalidades; b) pesquisa em campo utilizando-se de técnicas de observação; e c) entrevistas com membros das comunidades.

$\mathrm{O}$ artigo inicia tratando do tema chave de pesquisa, ou seja, os padrões espaciais de povoamento, apresentando categorias e conceitos. Em seguida, apresenta-se uma caracterização das comunidades de faxinal, no que se refere às singularidades de suas relações socioespaciais e formas de ocupação e uso do solo. Na última parte, são apresentados modelos dos diferentes padrões das estruturas de povoamento encontrados. 


\section{PADRÕES ESPACIAIS DE POVOAMENTO: CATEGORIAS E CONCEITOS}

Determinados fatores locacionais são decisivos para os grupos se firmarem em determinado espaço e, agindo de acordo com sua cultura e necessidades, o transformarem. “Os rios, as montanhas, os solos e outras condições físicas servem como base para a existência de interesses comuns" por se apresentarem enquanto recursos que são de interesse do grupo. Tem-se que, "ao mesmo tempo, também existem fatores mais especificamente sociais, que contribuem para a formação e adaptação dos grupos", e também fatores físicos, que podem facilitar a relação do grupo no local habitado (LEONARD e CLIFFORD, 1971, p. 60).

Portanto, "ao se examinar as relações de uma população com determinado espaço", verifica-se logo que "a distribuição dos indivíduos, dos grupos e das organizações não se faz ao acaso, mas obedece a princípios ou leis que podem ser, cientificamente, determinados" (VASCONCELOS, 1977, p. 46). Ou seja, analisando os grupos, sua localização e estruturas de povoamento, pode-se afirmar que estas não se configuram de tal forma por um acaso, pois sempre há um motivo, um objetivo, que leva o homem a se organizar daquela forma.

O local de sobrevivência, ou o "habitat", como afirma Mendras (1978, p. 31), "tanto para o homem como para os animais [...] designa a organização de um lugar para nele construir uma residência que seja ao mesmo tempo habitação, refúgio, local de trabalho". $\mathrm{O}$ autor ainda afirma que "O habitat é também um reflexo da sociedade que abriga" (p. 33), ou seja, corrobora Vasconcelos (1971) no sentido de que cada grupo se organiza de acordo com suas necessidades, e assim, o espaço apropriado torna-se um reflexo das especificidades do grupo.

Tendo em vista essas afirmações, parte-se para a exposição dos padrões de povoamento, que são parte fundamental desta dinâmica do homem na comunidade, buscando entender quais são as formas e estruturas de povoamento utilizadas pelos grupos para se organizarem sobre o espaço. A discussão se dá através do que foi estudado por autores como Smith (1967), Leonard e Clifford (1971), Smith (1971), Bertrand (1973), Vasconcelos (1977) e Mendras (1978). Os conceitos destes autores foram analisados e agrupados de acordo com as tipologias que eram comuns entre eles.

A primeira tipologia apresentada se refere às comunidades lineares, que, como se pode observar no Quadro 1, tem como característica principal a localização das residências orientadas pelo sistema viário ou por um rio, ou pelo mar. As terras utilizadas para o plantio estão dispostas nos arredores da área da vivência. 
Quadro 1 - Padrão espacial de povoamento: aldeias/comunidades lineares

\begin{tabular}{|c|c|}
\hline Autor & \multicolumn{1}{c|}{ Conceito } \\
\hline $\begin{array}{c}\text { Smith } \\
\text { (1967, pp. 275-283) }\end{array}$ & $\begin{array}{l}\text { O povoado linear assemelha-se muito à forma de aldeia nucleada, onde as } \\
\text { residências dos agricultores se encontram próximas umas das outras. Contudo, } \\
\text { no povoado linear, cada agricultor vive em seu terreno, e não afastado dos } \\
\text { campos onde ele efetua suas plantações. Os terrenos de residências estendem-se } \\
\text { ao lado de uma linha comum, como uma estrada, riacho ou praia. }\end{array}$ \\
\hline $\begin{array}{c}\text { Leonard e Clifford } \\
(1971, \text { p.74) }\end{array}$ & $\begin{array}{r}\text { Há o grupo de vizinhança e os serviços estão concentrados no povoado maior ou } \\
\text { aldeia. Os agricultores saem todos os dias para a roça, regressando, à tarde, ao } \\
\text { povoado. As residências se encontram geralmente em linha ao lado de um rio ou } \\
\text { estrada, ou ao redor de uma praça principal e das terras comunais. }\end{array}$ \\
\hline $\begin{array}{c}\text { Bertrand (1973, p. 101) } \\
\text { Vasconcelos } \\
(1977, \text { p. 49) }\end{array}$ & $\begin{array}{r}\text { As casas se encontram dispostas em fila em ambos os lados de um riacho ou } \\
\text { estrada, e a terra agricultánel está em longas e estreitas faixas estendendo-se por } \\
\text { trás das casas. }\end{array}$ \\
\hline $\begin{array}{l}\text { É o tipo modificado de aldeia comum, de modo a permitir que o indivíduo } \\
\text { esteja associado ao seu semelhante, em núcleo de concentração demográfica e, } \\
\text { residindo, ao mesmo tempo, dentro de sua própria terra. As aldeias em linha } \\
\text { se formam, em geral, ao longo das grandes estradas, das enormes rodovias, ou } \\
\text { então às margens dos rios. }\end{array}$ \\
\hline
\end{tabular}

Org.: SOARES, J. G. (2011).

Esse tipo de povoamento tem origem francesa e é bastante presente no Brasil. Foi usado, principalmente, em sistemas de colonização pública. Smith (1971), em sua viagem pelo Brasil, aponta sobre a presença deste tipo de organização no sul do país. Em seu diário de viagem, ele se refere, por exemplo, ao trecho de Curitiba no Paraná até Blumenau em Santa Catarina, apontando que:

O padrão de povoamento aqui é uma variedade bem definida do tipo de aldeia linear. Os vales são estreitos e o solo de fundo muito limitado e em certos lugares praticamente inexistente. Os sítios se alinham em ambos os lados do curso de água. Como se trata provavelmente de pequenos lotes dispostos desta maneira, há grande proximidade entre as casas (p. 246).

Vasconcelos (1977, p. 52) corrobora com as afirmações de Smith (1971), afirmando que "A localização dessas aldeias em linha se observa, de preferência, nos estados do Paraná, Santa Catarina e Rio Grande do Sul".

Ao analisar esta tipologia de povoamento, Smith (1967) aponta a existência destes padrões em Portugal e na Espanha. Para ele, dois fatores são determinantes na origem dessas comunidades, certos aspectos particulares da paisagem e imperativos culturais e hábitos locais.

A segunda tipologia diz respeito às comunidades/aldeias nucleadas (Quadro 2). Elas têm sua estrutura de povoamento orientada por um elemento central, seja ele a escola, a igreja, ou outro elemento de uso comunitário. As áreas de cultivo estão distribuídas nos arredores da comunidade. Tem como ponto negativo o econômico, uma vez que as terras utilizadas para o plantio estão distantes das residências, o que obriga o produtor a se deslocar até elas e dificulta as tarefas de cultivo (BERTRAND, 1973). 
Quadro 2 - Padrão espacial de povoamento: aldeia nucleada/configuração radial

\begin{tabular}{|c|l|}
\hline Autor & \multicolumn{1}{c|}{ Conceito } \\
\hline $\begin{array}{c}\text { Smith } \\
\text { 1967, pp. 275-283) }\end{array}$ & $\begin{array}{l}\text { São aquelas em que as residências dos lavradores se agrupam longe da gleba } \\
\text { onde trabalham. Um traço característico desse tipo de povoamento é que os } \\
\text { agricultores não vivem na gleba, mas devem deslocar-se diariamente do centro } \\
\text { do povoado para o campo a fim de executar as tarefas rotineiras da agricultura. }\end{array}$ \\
\hline $\begin{array}{c}\text { Bertrand } \\
(1973, \text { p. 101) }\end{array}$ & $\begin{array}{l}\text { A característica mais evidente é que as casas dos agricultores estão aglomeradas, } \\
\text { e as terras de plantio se encontram distante de sua residência. Não é raro } \\
\text { os animais e aves partilharem dos alojamentos do proprietário ou serem } \\
\text { abrigados próximos dali. As aldeias variam em suas formas, mas normalmente } \\
\text { são circulares ou retangulares ou de contornos irregulares. Há uma forte } \\
\text { organização social interligada, devido à proximidade das residências. }\end{array}$ \\
\hline $\begin{array}{c}\text { Vasconcelos } \\
(1977, \text { p. 49) }\end{array}$ & $\begin{array}{l}\text { Aldeia de forma circular, no centro, ficam os edifícios públicos e as sedes } \\
\text { das instituições mais importantes, como a igreja, a escola. Os terrenos da } \\
\text { comunidade se estendem no entorno, em forma também circular e concêntrica, } \\
\text { sendo a primeira faixa destinada às culturas, a segunda às pastagens, e a terceira } \\
\text { às reservas florestais. }\end{array}$ \\
\hline $\begin{array}{c}\text { Mendras } \\
(1978, \text { p. 33) }\end{array}$ & $\begin{array}{l}\text { É uma aglomeração compacta de uma ou várias centenas de casas. A aldeia } \\
\text { agrupada pode abrigar uma intensa vida comunitária. Este tipo de habitat } \\
\text { presta-se, evidentemente, melhor às atividades coletivas. }\end{array}$ \\
\hline
\end{tabular}

Org.: SOARES, J. G. (2011).

Smith1 (1953, apud, BERTRAND, 1973, p. 99) coloca que "em termos de número de pessoas afetadas, a forma de colonização do tipo aldeia nucleada é, de longe a mais importante do mundo". Este tipo de comunidade podia ser encontrado nos Estados Unidos, tendo em vista a influência da colonização inglesa, e também sendo presente na Alemanha, Rússia, Itália, Suíça, Espanha e outros (VASCONCELOS, 1977).

No Brasil, segundo aponta Anjos (2009, p. 114), as ocorrências deste tipo são verificadas principalmente na região nordeste, centro-oeste e sul do país, em comunidades quilombolas, e pode ter influência de comunidades indígenas.

A terceira tipologia de povoamento se refere às organizações com estrutura esparsas ou as fazendas dispersas (Quadro 3). Caracterizam-se pela distância entre as residências, ou seja, dificilmente há um núcleo de vizinhança habitado por agricultores, o que pode haver é um núcleo comercial, no qual as famílias se abastecem de medicamentos, gêneros alimentícios e onde pode estar a igreja e a escola (VASCONCELOS, 1977).

Quanto ao núcleo comercial, Bertrand (1973, p. 101) define-o como espaço onde "se efetuam as trocas e também se obtêm outros serviços". Salienta que o centro comercial toma a forma de comunidade, estando esta localizada a certa proximidade do povoamento disperso. 
Quadro 3 - Padrão espacial de povoamento: Estrutura com residências dispersas

\begin{tabular}{|c|c|}
\hline Autor & Conceito \\
\hline $\begin{array}{c}\text { Smith } \\
\text { (1967, pp. 275-283) }\end{array}$ & $\begin{array}{c}\text { Caracteriza-se por uma forma particular de o agricultor se organizar e } \\
\text { viver no campo, onde as residências não ficam próximas umas das outras, } \\
\text { criando assim o padrão das propriedades isoladas ou dispersas. Esta for- } \\
\text { ma também pode ser conceituada como fazendas dispersas. }\end{array}$ \\
\hline $\begin{array}{c}\text { Leonard e Clifford } \\
(1971, \text { p.74) }\end{array}$ & $\begin{array}{c}\text { Nas comunidades de residências dispersas, as famílias vivem em suas } \\
\text { próprias terras e, muitas vezes, constroem a residência mais ou menos no } \\
\text { centro da propriedade. Em tal caso, é usual encontrar os serviços econô- } \\
\text { micos e ações sociais localizados num lugar estratégico. }\end{array}$ \\
\hline Vasconcelos (1977, p. 49) & $\begin{array}{c}\text { Este tipo de povoamento consiste na difusão dos grupos pela área geo- } \\
\text { gráfica. Ao contrário da aldeia ou vila rural, o povoamento se caracteriza, } \\
\text { sobretudo, pela fixação do fazendeiro na área por ele explorada. }\end{array}$ \\
\hline Mendras (1978, pp. 30-33) & $\begin{array}{c}\text { Dentre as formas de habitat rural, o agricultor constrói sua casa no seu } \\
\text { próprio campo de plantação e criação, isolado dos seus congêneres e afas- } \\
\text { tado dos vizinhos. }\end{array}$ \\
\hline
\end{tabular}

Org.: SOARES, J. G. (2011).

Esse tipo de povoamento é predominante nos Estados Unidos. Já no Brasil, há manifestações nos estados de Minas Gerais, Mato Grosso e Maranhão, onde estas propriedades isoladas dominam a paisagem (SMITH, 1971; VASCONCELOS, 1977). Da mesma forma, pode ser observado no sul do país, nas denominadas estâncias pampianas.

No Brasil, esse tipo de povoamento foi predominante até meados do século XIX tendo perdurado mais de 300 anos. Desde o início, o Brasil tinha "[...] um povo de latifundiários", fato que se deu durante o período colonial, e que "a história da pequena propriedade, pode-se dizer que data de apenas um século" (VIANNA², apud, SMITH, 1971, p. 150). Portanto, isso muda a partir de meados e final do século XIX, quando começam a aparecer no território brasileiro as pequenas propriedades, que geram as vizinhanças e comunidades, de acordo com sua evolução, e que são povoadas principalmente por imigrantes (SMITH, 1971, p. 150).

Como se observa, ao analisar as formas de povoamento, há certa dualidade entre as comunidades lineares e nucleadas, que são formadas por pequenos proprietários, e as estruturas de povoamento esparsas, onde há predomínio dos grandes proprietários, das fazendas, tendo em vista os apontamentos dos autores aqui analisados. Certamente as estruturas de povoamento esparsas são geradas pela existência de grandes propriedades, sendo que estas grandes extensões de terra pertencem a um só dono ou família, a qual é habitada por esta.

Essa dualidade, entre a fazenda e os pequenos proprietários, é bastante presente não só no Brasil, mas em grande parte da América Latina, e o que se nota é que estas formações ocorrem com base em lógicas diferenciadas, o que leva a configurações espaciais de povoamento e uso do solo também distintas, devido a dinâmicas que ocorrem no tempo e no espaço, permeadas por fatores sociais e principalmente econômicos (SAHR, 2005).

2 Smith (1971) não apresenta referências sobre a citação feita de Oliveira Vianna. 
Uma vez apresentados as categorias e os conceitos referentes às comunidades e suas formas de organização no espaço de vivência, a seguir, aprofunda-se a discussão em torno de uma modalidade específica de comunidade encontrada no sul do Brasil, as comunidades faxinalenses, buscando caracterizá-las no que diz respeito às suas relações socioespaciais e suas formas de povoamento, ocupação e uso do solo.

\section{SINGULARIDADES ESPACIAIS DAS COMUNIDADES FAXINALENSES}

As comunidades de faxinal, bem como seus moradores, possuem características particulares que as diferenciam das demais comunidades rurais. Neste sentido, esta seção tem por objetivo apresentar as singularidades dessa modalidade de comunidade tradicional quanto às suas relações socioespaciais e as suas formas de ocupação e uso do solo.

Os faxinais se configuram enquanto comunidades tradicionais típicas, que estão localizadas na região das Matas com Araucária do Paraná. São consideradas tradicionais, devido a uma série de aspectos culturais diferenciados que têm origem em meados do século XIX, e por possuírem uma forma particular de organização socioespacial (CHANG, 1988). Outro ponto, que as faz serem assim denominadas, se refere ao uso que dão ao espaço e aos recursos naturais nele existentes, que são condição e base para sua reprodução cultural, social, religiosa, ancestral e econômica, utilizando conhecimentos, inovações e práticas geradas e transmitidas pela tradição (BRASIL, 2007).

Salientando as características principais dos povos faxinalenses, Löwen Sahr (2005, p. 57) apresenta uma série de elementos de autoidentificação destes, que podem ser observados no Quadro 4.

Quadro 4 - Elementos de autoidentificação dos povos faxinalenses

\section{Elemento de identificação}

- Associam a pecuária, a agricultura e o extrativismo, num sistema singular.

- Partilham o chão, ou seja, as terras do criadouro são de uso comum.

- Criam de forma coletiva animais de pequeno e grande porte soltos e misturados.

- Praticam uma agricultura de subsistência com instrumentos tradicionais (enxada, tração animal).

- Partilham as sementes, criações, produtos através de trocas.

- Praticam uma cultura de extrativismo (erva-mate, madeira, pinhão).

- Desenvolvem uma atividade agroflorestal e prezam pela conservação da biodiversidade.

- Possuem uma forte convivência e integração com o meio ambiente.

- Possuem uma história e uma cultura própria.

- Preservam e respeitam as suas tradições, os seus costumes e a sua cultura (festas, rezas).

- Praticam uma religiosidade popular.

- Apresentam uma vida comunitária, solidária e de união.

- Integram em sua convivência famílias com terra e famílias que não tem terra.

- Possuem normas e fazem acordos baseados na cultura e tradição.

- Trabalham de forma solidária em Mutirões/Puxirões.

- Partilham os bens, os serviços e os conhecimentos.

- Lutam pela sobrevivência.

- Possuem alegria de viver, amor a natureza, liberdade, esperança, confiança e união.

Fonte: LÖWEN SAHR, C. L. (2005). 
No Quadro 4, está apresentado o conjunto de relações que ocorre entre os faxinalenses. Estas relações de dependência para com a natureza e de luta baseada em sua tradição e cultura, envolvendo um espaço comunitário, têm nos laços de solidariedade o seu cerne. Isso evidencia o quanto as comunidades de faxinal são exemplo de singularidade.

Partindo-se desta discussão, pode-se afirmar, portanto, que as comunidades de faxinal, como uma forma de organização ainda presente na região Centro-Sul do estado do Paraná, mantêm, mesmo em meio a diversas dinâmicas, uma forma particular de organização espacial, que se traduz na divisão das terras para uso, na criação extensiva de animais para tração e consumo em áreas comuns, assim como, pela extração florestal dentro do criadouro comum, principalmente da erva-mate, que desempenha um papel de renda complementar. Também apresentam como particularidades a policultura alimentar de subsistência e a produção comercial nas terras de plantio.

Identificar tipologias espaciais de povoamento para comunidades de faxinais é o eixo da análise aqui proposta. Assim, torna-se necessário apontar as singularidades das comunidades de faxinais, que serão destacadas nas espacializações presentes na próxima seção. Existem alguns elementos que são comuns a todas as estruturas e outros que são singulares a determinados tipos de povoamento. Entre estes elementos, tem-se que:

a) Um dos fatores intrínsecos que são apontados na espacialização dos faxinais se refere às terras de criação e às terras de planta. Para que os animais não entrem nas terras de planta, a área de criação é toda cercada. Cabe salientar que, dependendo da tipologia de povoamento, as terras de planta ficam próximas ou distantes das residências.

b) Nos acessos as terras de criar pelas estradas principais têm-se o mata-burro e, ao lado deste, um portão. O mata-burro impede a saída dos animais da área do criadouro comum, já o portão permite que transitem, de forma controlada, animais e, consequentemente, carroças. No acesso pelas estradas secundárias é mais comum somente a presença do portão.

c) Outro fator comum às comunidades de faxinal é que as residências são instaladas principalmente nas proximidades de cursos d'água. A presença de um rio de primeira ordem, ou de seus afluentes, é fundamental pela necessidade de água para o consumo dos animais e também para consumo humano. Próximo destes é mais fácil se obter sucesso na perfuração de um poço para uso doméstico.

d) Mais uma característica que é inerente a este tipo de comunidade diz respeito às áreas de mata. Nas proximidades das áreas com residências, é comum existirem grandes áreas de campos com pastos, além de mata rala. A certa distância de onde se encontram as residências, nota-se a existência de mata mais densa. Nestas áreas de campos e matas, os animais são criados soltos, tendo acesso direto a fontes de alimento.

e) Um elemento bastante característico destas comunidades são os quintais e hortas, que ficam ao lado das residências. Estes espaços são cercados para evitar 
que os animais, criados à solta, entrem e estraguem as frutas, verduras, legumes e ervas medicinais.

f) Podem ser encontrados ainda espaços maiores, também cercados. Trata-se de potreiros, locais onde as famílias fecham as fêmeas que estão para ter filhotes ou animais que serão utilizados no dia seguinte para o deslocamento até as terras de planta para serem utilizados como tração (Ex. cavalos).

g) Pode haver famílias que não se utilizam do criadouro da comunidade, tendo sua criação alta solta em potreiros individualizados, que podem abrigar em seu interior a residência e os quintais. Existem casos em que estes potreiros abrigam pequenos chiqueiros, nos quais os suínos criados à solta são fechados para a desvermifugação, engorda e abate.

h) Quanto aos elementos comunitários, são mais comuns nestas comunidades, a capela, a escola e o posto de saúde. Em algumas comunidades, pode haver somente a presença da capela, já que muitas escolas rurais foram fechadas, quando ocorreu a nuclearização da educação ${ }^{3}$ entre as décadas de 1990 e 2000. Os postos de saúde geralmente estão nas comunidades que possuem maior número de habitantes, atendendo a membros de comunidades vizinhas com menor número de habitantes, que não possuem a unidade de saúde municipal.

Tendo apresentado algumas singularidades das comunidades faxinalenses, busca-se, neste momento, aprofundar o estudo, a partir da análise de tais comunidades no que se refere a seus padrões e estruturas espaciais de povoamento.

\section{PADRÕES ESPACIAIS FAXINALENSES: ESTRUTURAS E USOS}

Algumas comunidades tendem a delinear relações e processos sociais similares, assim como, há aquelas, que devido a fatores particulares, apresentam dinâmicas mais inerentes. Estas se transformam e se reorganizam no que concerne às relações entre os membros e, também, nas suas formas de uso do espaço de vivência.

Desta feita, essas dinâmicas acabam por influir nas formas de povoamento, elemento característico da espacialidade faxinalense. Partindo desta premissa, o intuito desta seção é trazer um panorama das formas espaciais de povoamento em comunidades de faxinal.

Existem espacialidades distintas entre as comunidades, mas também similaridades, o que possibilita apontar para padrões de povoamento em faxinais. Para apresentar tais espacialidades, foram criados croquis, tendo como base as características espaciais observadas e analisadas em diversas comunidades faxinalenses.

Tomando-se por base os elementos que produzem singularidades nestas comunidades, apresentados na seção anterior, parte-se agora para a exposição das espacialidades e padrões de povoamento intrínsecos aos faxinais. Com base no estudo

3 Para mais informações sobre a nuclearização e reorganização do ensino, ver Simões (2009). 
das comunidades faxinalenses, quatro tipologias puderam ser identificadas: povoamento nuclear; povoamento linear; povoamento polinuclear e povoamento com estrutura mista.

a) Faxinais com estrutura de povoamento nucleada

Esta tipologia pode ser observada em comunidades de faxinal que não vivenciaram muitas mudanças, mesmo naquelas onde vem ocorrendo aumento da população. Nela há um núcleo que concentra as residências próximas aos elementos comunitários ${ }^{4}$. As terras de planta estão fora da área de criação, para as quais os habitantes se deslocam diariamente para trabalhar na agricultura. Estas comunidades apresentam contornos irregulares, mas o que as caracteriza é a proximidade ao elemento de uso comum e a maior distância da residência das terras de planta (Figura 1).

Figura 1 - Faxinais com estrutura de povoamento nucleada

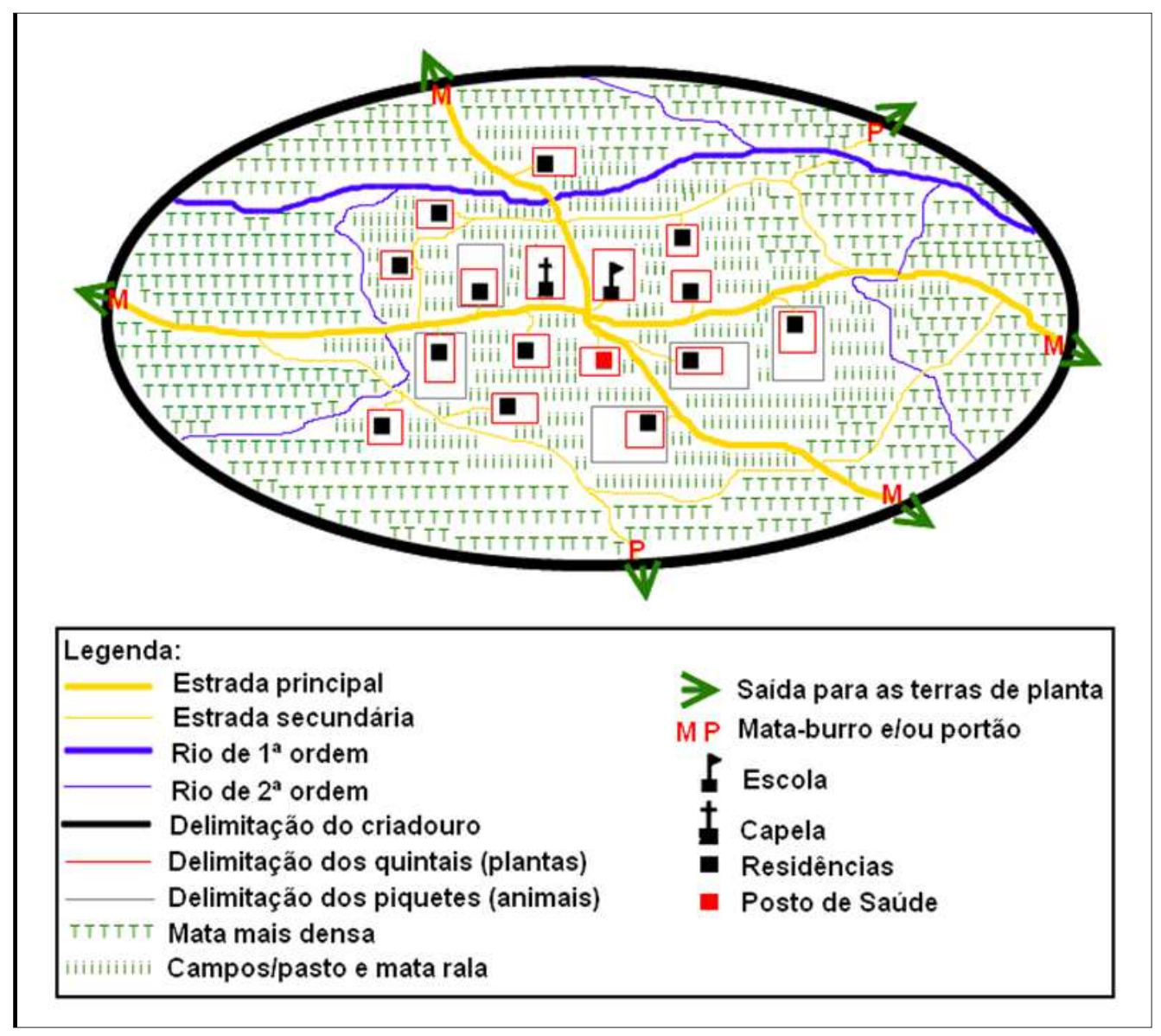

Org.: SOARES, J. G. (2012).

Neste tipo de organização, há uma tendência de maior integração entre seus membros, já que as residências estão próximas umas das outras. Isso faz com que o sentido de comunidade seja mais intenso e os processos sociais mais solidários, tendo forte participação e interação sociais.

4 Um exemplo de comunidade que apresenta esta tipologia de povoamento é Água Quente dos Meiras, situada no município de Rio Azul-PR, na região Centro-Sul do Estado (SOARES, 2012). 
Observando a Figura 1, na qual é apresentado um croqui desta tipologia de povoamento, nota-se ao centro do núcleo residencial os elementos comunitários, sendo eles a capela, escola e posto de saúde. Nem sempre serão observados estes três elementos, mas é comum a presença da capela no centro desse tipo de comunidade. As residências estão distribuídas de forma concêntrica a esta, todavia, apresentando contornos irregulares. Nota-se também a presença de potreiros, contudo não é comum a presença de terras de planta no interior do criadouro.

b) Faxinais com estrutura de povoamento linear

Nesta tipologia, as residências se estendem ao longo e à beira das estradas ou rios/ cursos de água. Há numa área bem localizada da comunidade os elementos comunitários, como a igreja, a escola ou o posto de saúde ${ }^{5}$. As terras de planta estão localizadas imediatamente atrás das residências ou a certa distância destas, fora da área de criação, necessitando o deslocamento para se trabalhar na agricultura (Figura 2). Nos casos em que as terras estão nas áreas detrás das casas, isso pode ser considerado um sinal de desestruturação de um elemento fundamental do faxinal, que é o criadouro coletivo.

Figura 2 - Faxinais com estrutura de povoamento linear

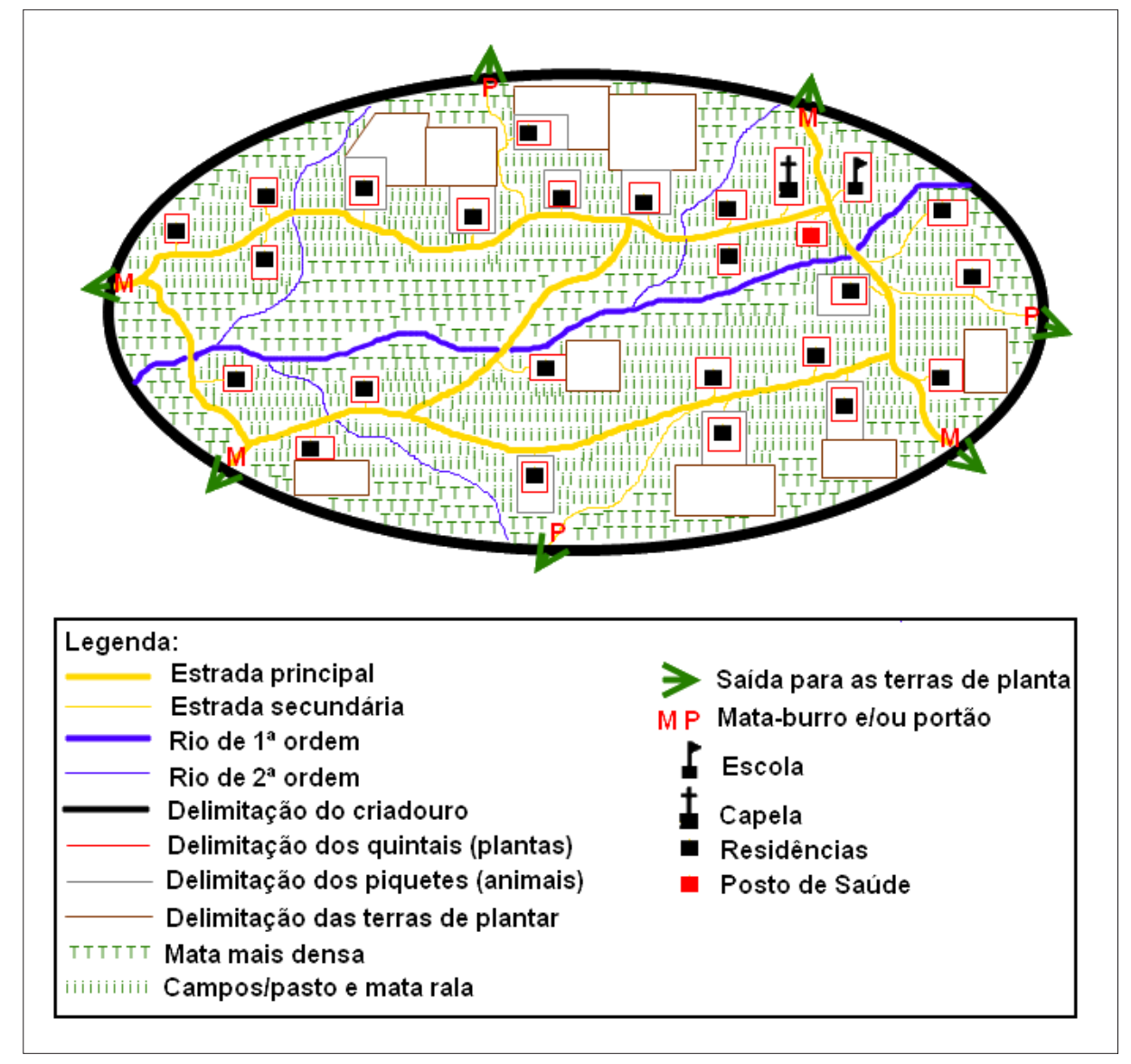

Org.: SOARES, J. G. (2012).

5 Uma comunidade que apresenta esta tipologia de povoamento é a de Vila Nova, situada no município de Rio Azul-PR na região Centro-Sul do Estado (SOARES, 2012). 
Observando a Figura 2, onde são apresentadas as formas de povoamento linear, nota-se como principal característica a distribuição das residências ao longo dos cursos de água e das estradas, duas facilidades eminentes para os membros da comunidade. Os rios servem de fonte de água para os animais e a proximidade às estradas facilita $\mathrm{o}$ deslocamento, acesso a energia elétrica, telefonia rural e, em algumas comunidades, a água tratada. Neste tipo de povoamento, não se nota a presença de um núcleo residencial principal.

A disposição das terras de planta também varia, diferindo da existente nas comunidades nucleadas, já que existem terras de planta por detrás dos potreiros, além de que, há localização das residências nas proximidades das divisas entre terras de criar e de plantar. Assim, as residências ficam mais próximas de suas terras de planta, facilitando o acesso às áreas de agricultura. Esta proximidade é mais um fator peculiar desta forma de povoamento.

Esta tipologia é bastante comum em comunidades com maior número de habitantes e onde, em sua gênese, apresentavam uma forma de povoamento mais esparsa. Acredita-se que as propriedades eram maiores e que por meio da divisão por herança, os filhos foram instalando suas casas à beira da estrada, nos terrenos que eram de seus pais, gerando assim tal particularidade.

Quanto aos rios, cabe apontar que em muitas comunidades a estrada, quando da sua construção, seguiu os contornos dos rios. Assim, uma característica que pode ser apontada nesta tipologia é a proximidade das residências a estes dois elementos estruturais.

No caso apresentado na Figura 2, observa-se um rio de primeira ordem no centro da comunidade. As residências estão na área mais baixa, ficando as terras de planta nas encostas. As terras mais baixas, ou seja, próximas aos rios não eram boas para a agricultura quando da gênese destas comunidades, pois à época não havia insumos químicos para a correção destas. Já as terras localizadas em locais mais altos apresentavam melhores condições para a agricultura. Sendo assim, a forma mais propícia para utilizá-las foi como área de criação e residência, deixando as terras mais altas e férteis para a agricultura. Isso acaba também por influir e caracterizar esta estrutura de povoamento.

c) Faxinais com estrutura de povoamento polinuclear

Esta tipologia assemelha-se às configurações da comunidade com estrutura nucleada, contudo, há normalmente um núcleo principal, com maior número de habitantes ou elementos comunitários, tendo nos arredores núcleos menores ${ }^{6}$. Pode-se também encontrar diversos núcleos com certa similaridade em tamanho. Os núcleos apresentam algum dos elementos comunitários, como a capela, a escola ou o posto de saúde. As terras de planta estão fora da área de criação, para as quais os habitantes se deslocam diariamente para trabalhar na agricultura (Figura 3).

6 Uma comunidade que apresenta esta tipologia de povoamento é a de Lageado dos Mello, situada no município de Rio AzulPR, na região Centro-Sul do Estado (SOARES, 2012). 
Figura 3 - Faxinais com estrutura de povoamento polinuclear

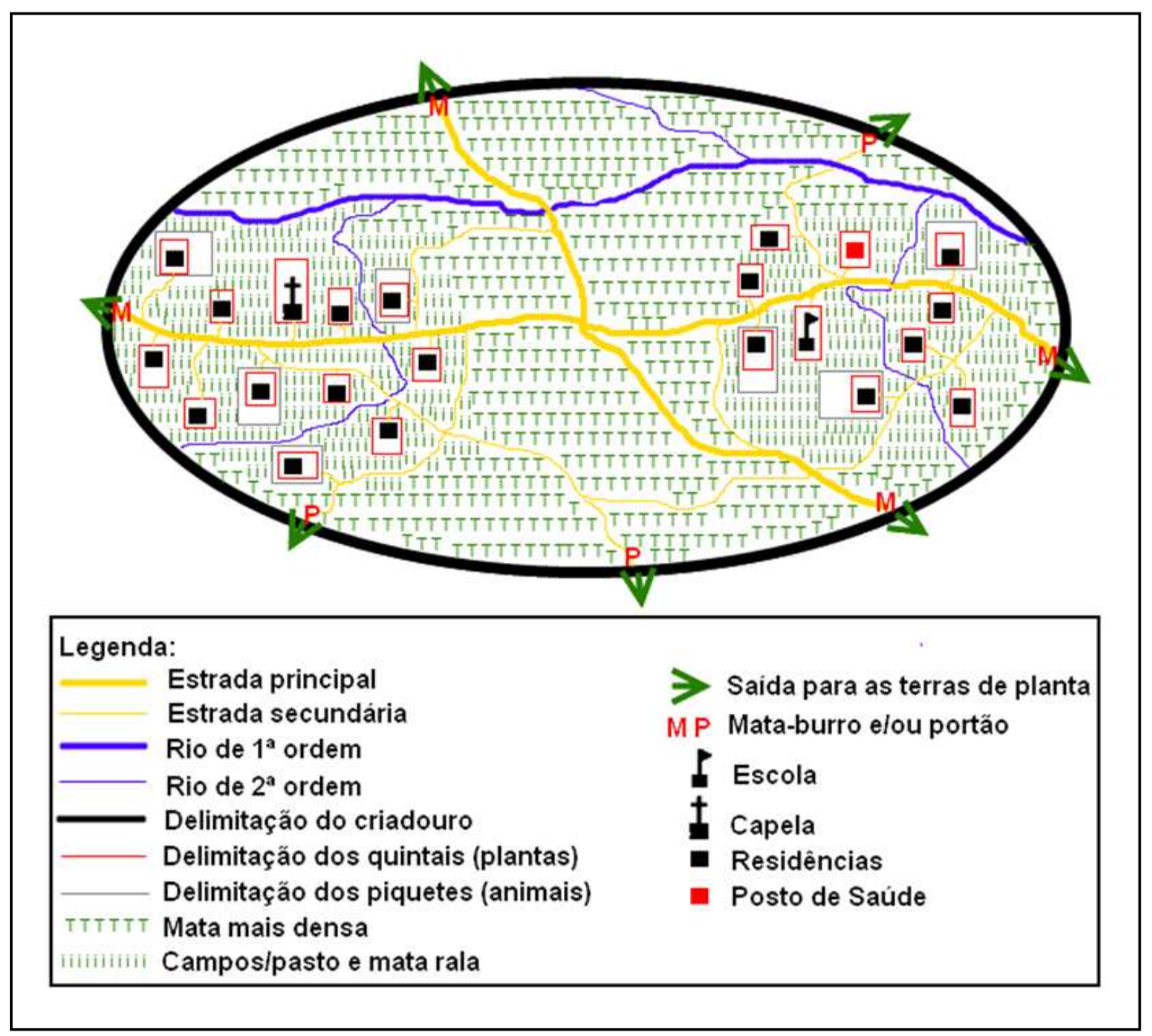

Org.: SOARES, J. G. (2012).

Observando a Figura 3, onde está representada a forma de povoamento polinuclear, nota-se a existência de dois núcleos de povoamento, sendo que um deles abriga a capela e o outro, a escola e o posto de saúde. As residências estão localizadas de forma concêntrica aos equipamentos comunitários.

As áreas de mata mais rala e campos estão nas proximidades das residências, havendo entre estes um espaço de mata mais densa. Não há terras de planta no interior do espaço de criação, contudo, há presença de piquetes. No interior dos núcleos, nota-se a presença de rios de segunda ordem, que como já salientado, se apresentam como uma facilidade para os membros da comunidade.

d) Faxinais com estrutura de povoamento mista

Neste tipo de comunidade, pode-se observar a existência das duas formas de povoamento mais comuns, tanto a de estrutura nucleada como a linear ${ }^{7}$, podendo se sobressair uma das tipologias (Figura 4).

7 Exemplos de comunidades que apresentam esta tipologia de povoamento são as de Marumbi dos Elias e Faxinal de São Pedro, situadas no município de Rio Azul-PR, na região Centro-Sul do Estado (SOARES, 2012). 
Figura 4 - Faxinais com estrutura de povoamento mista

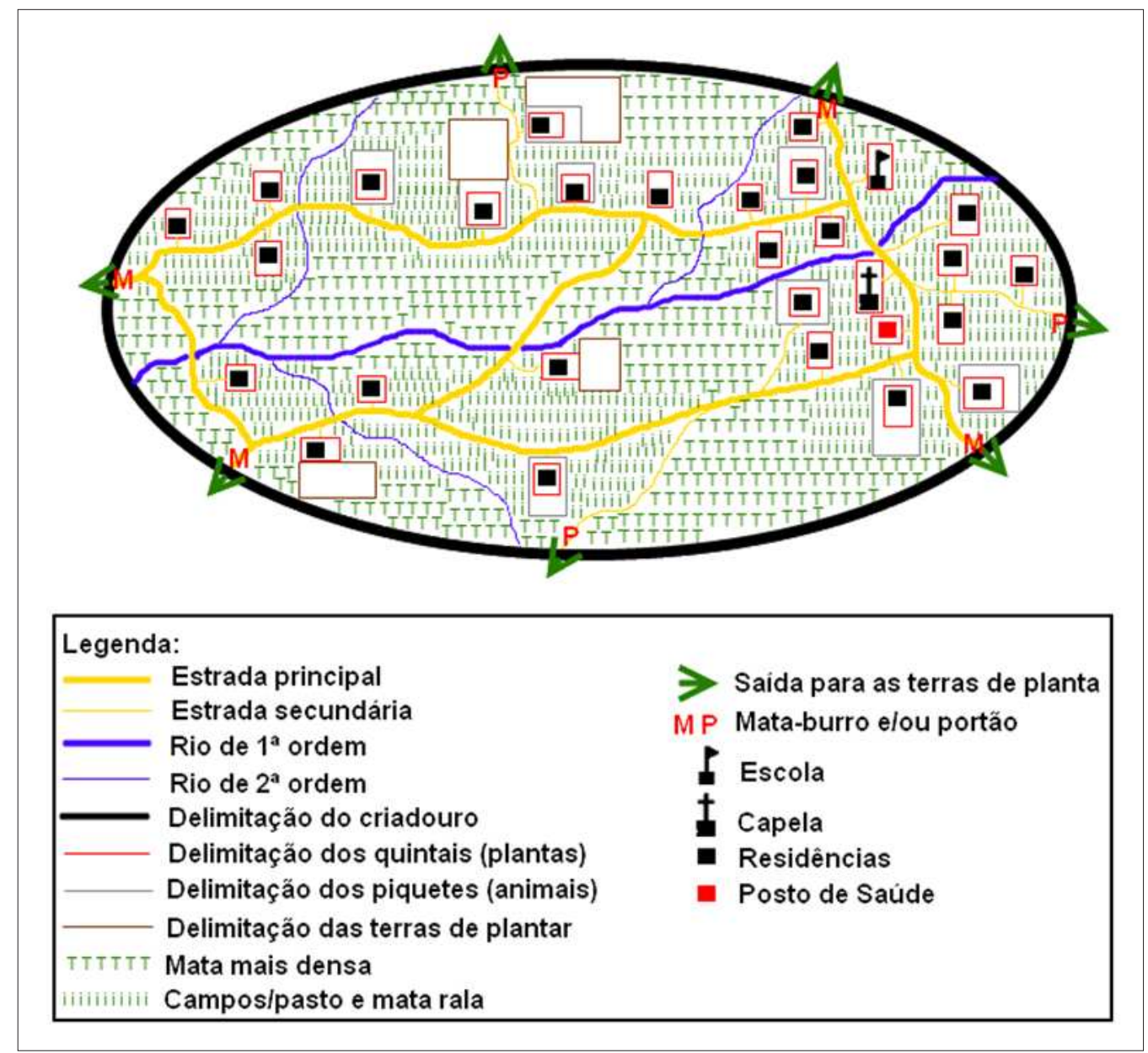

Org.: SOARES, J. G. (2012).

Ao observar a Figura 4, pode-se notar que há um núcleo principal, no qual se encontram os elementos comunitários, sendo estes a capela, a escola e o posto de saúde. Há uma concentração de residências nas proximidades, caracterizando a forma de comunidade nucleada. Contudo, há também, a certa distância deste núcleo, residências que acompanham a beira das estradas e rios, apontando para características de comunidade linear. Nestas, as terras de planta encontram-se mais próximas. Tem-se assim, uma simbiose entre povoamento nuclear e linear.

Esta tipologia tem uma ligação eminente com a gênese e dinâmica da comunidade. Uma comunidade que em um primeiro momento apresentava um núcleo, assumindo a forma de aldeia nucleada, em função de seu crescimento produzirá novos espaços povoados, que vão tomar formas de aldeia linear devido às facilidades de localização das residências. Pode, todavia, ocorrer o contrário, ou seja, uma comunidade que em um primeiro momento apresentava-se como aldeia linear, em função da instalação de novos elementos comunitários, produzirá a concentração de novas residências concêntricas a estes. 


\section{CONSIDERAÇÕES FINAIS}

Cada comunidade apresenta aspectos intrínsecos, que geralmente derivam da cultura do povo que a integra, dos seus hábitos e necessidades. Estes aspectos se sobressaem através de ações cotidianas, executadas pelos membros das comunidades, formando, por meio de uma dinâmica temporal, espaços adaptados à sua vivência, de acordo com suas necessidades.

Isso resulta da necessidade que os seres humanos apresentam de viver em comunidade, pois esta, depois de sua família, é para o homem seu ponto maior de referência, já que dali sua vida parte e tem suas bases. Este lugar de convivência, sempre acaba sendo um berço de seu maior aprendizado, e é ali onde ele primeiramente se envolve com a cultura.

É na comunidade que a pessoa tem seu aprendizado social e é guiada a como agir perante os membros daquela organização socioespacial, e também da sociedade como um todo. Sendo assim, a comunidade tem um papel fundamental na formação do homem para sua introdução na sociedade.

Como se pôde observar, as comunidades faxinalenses apresentam uma cultura singular, com uma série de características que as tornam um exemplo ingente de comunidade. Toda a lógica que rege as ações no interior destas tem nas relações tradicionais de solidariedade e compadrio o ponto chave e isso se reflete em diferentes espacialidades.

Identificar tipologias espaciais de povoamento para comunidades de faxinais foi importante e inédito, uma vez que nada semelhante foi apresentado até então em estudos referentes aos faxinais. Com base no estudo das comunidades faxinalenses, quatro tipologias puderam ser identificadas: povoamento nuclear; povoamento linear; povoamento polinuclear e povoamento com estrutura mista. Buscou-se, assim, suprir tal lacuna nos estudos, bem como, possibilitar uma nova forma de análise de faxinais, que parte de suas estruturas espaciais.

\section{REFERÊNCIAS}

ANJOS, Rafael Sanzio Araújo dos. Quilombos: geografia africana, cartografia étnica, territórios tradicionais. Brasília: Mapas Editora e Consultoria, 2009.

BERTRAND, Alvin L. Sociologia rural: uma análise da vida rural contemporânea. Porto Alegre: Atlas, 1973.

BRASIL. DECRETO n ${ }^{\circ} 6040$ de 07 de fevereiro de 2007. Institui a Política Nacional de Desenvolvimento Sustentável dos Povos e Comunidades Tradicionais. Diário Oficial da União, Brasília, DF: 08 de fev de 2007, p. 316.

CHANG, Man Yu. Sistema Faxinal: uma forma de organização camponesa em desagregação no Centro-Sul do Paraná. IAPAR, Boletim Técnico. Londrina, 1988.

LEONARD, Olen. CLIFFORD, Roy. A sociologia rural para os programas de ação. São Paulo: Pioneira, 1971.

LÖWEN SAHR, Cicilian Luiza. Faxinalenses: populações tradicionais no bioma da mata com araucária? Anais do $1^{\circ}$ ENCONTRO DOS POVOS DOS FAXINAIS. Irati: 2005. 
MENDRAS, Henri. Sociedades camponesas. Rio de Janeiro: Zahar Editores, 1978.

NERONE, Maria Madalena. Terras de Plantar, Terras de Criar - Sistema Faxinal - Rebouças - 1950 - 1997. 2000. Tese (Doutorado em História) - Universidade Estadual Paulista.

SAHR, Wolf-Dietrich. Micro-dynamics in the rural space of central Paraná a contribution to regional rural Geography. III SIMPÓSIO BRASILEIRO DE GEOGRAFIA AGRÁRIA - II SIMPÓSIO INTERNACIONAL DE GEOGRAFIA AGRÁRIA - JORNADA ARIOVALDO UMBELINO DE OLIVEIRA. Anais de artigos. UNESP, Presidente Prudente - SP, 2005.

SIMÕES, Willian. Comunidades tradicionais de Faxinal e gestão de políticas públicas educacionais no estado do Paraná: compreendendo territórios e territorialidades. 2009, 140p. Dissertação (Mestrado em Gestão do Território) - Universidade Estadual de Ponta Grossa, Paraná.

SMITH, T. Lynn. Brasil: povo e instituições. Aliança para o Progresso. USAID, Rio de Janeiro, 1967.

SMITH, T. Lynn. Organização Rural. São Paulo: Editora da Universidade de São Paulo, 1971.

SOARES, Joélcio Gonçalves. Comunidades faxinalenses no município de Rio Azul-PR: gênese, características e transformações nos padrões espaciais de povoamento. Ponta Grossa, 2012. 200p. Dissertação (Mestrado em Gestão do Território) - Universidade Estadual de Ponta Grossa.

VASCONCELOS, Edgard. Sociologia rural. Imprensa Universitária - Universidade Federal de Viçosa. Viçosa, 1977.

Recebido em 21/08/2012

Aceito para publicação em 10/10/2012 